\title{
Final Report for
}

\section{LWR Passive Safety}

Providing the Basis for Innovative Improvements in Advanced LWR Reactor

Passive Safety Systems Design: An Educational R\&D Project

Award Number

DE-FG07-03ID14500

Report Date

February 27, 2007

For the Period

July 16, 2003 through July 15, 2006

Submitted to:

The U. S. Department of Energy (DOE)

Nuclear Engineering Education Research (NEER) Program 
Project Title: $\quad$ Providing the Basis for Innovative Improvements in Advanced LWR Reactor Passive Safety Systems Design: An Educational R\&D Project

Covering Period: July 16, 2003 through July 15, 2006

Date of Report: $\quad$ February 27, 2007

Recipient: $\quad$ Idaho State University

College of Engineering

Campus Box 8046

Pocatello, ID 83209

Award Number: DE-FG07-03ID14500

Contact: $\quad$ Dr. Brian G. Williams

College of Engineering

Idaho State University

Pocatello, ID 83209

Phone: 208-282-4129

Project Team:

$\begin{array}{ll}\begin{array}{l}\text { Dianne Horrocks } \\ \text { Office of Sponsored Programs }\end{array} & \text { Richard R. Schultz } \\ \begin{array}{l}\text { Idaho State University } \\ \text { Pocatello, ID 83209 }\end{array} & \text { Mail Stop 3890 } \\ \text { Phone: 208-282-2592 } & \text { Idaho Falls, ID 83415 } \\ & \text { Phone: 208-526-9508 } \\ \text { Bill Phoenix } & \text { Hiral Kadakia } \\ \text { College of Engineering } & \text { Ph.D. Candidate } \\ \text { Idaho State University } & \text { Idaho State University } \\ \text { Idaho Falls, ID 83404 } & \text { Idaho Falls, ID 83404 } \\ \text { Phone: 208-525-7192 } & \text { Phone: 208-525-7192 }\end{array}$

Subcontractors: Dr. Jim C. P. Liou

University of Idaho

Moscow, ID 83844

Phone: 208-885-6202

\section{Project Objective:}

This project characterizes typical two-phase stratified flow conditions in advanced water reactor horizontal pipe sections, following activation of passive cooling systems. It provides (1) a means to educate nuclear engineering students regarding the importance of two-phase stratified flow in passive cooling systems to the safety of advanced reactor systems and (2) describes the experimental apparatus and process to measure key parameters essential to consider when designing passive emergency core cooling flow paths that may encounter this flow regime. Based on data collected, the state of analysis capabilities can be determined regarding stratified 
flow in advanced reactor systems and the best paths forward can be identified to ensure that the nuclear industry can properly characterize two-phase stratified flow in passive emergency core cooling systems.

\section{Background:}

The experiments performed to evaluate the Generation III Westinghouse AP600 advanced light water reactor (LWR) performance during loss-of-coolant accidents showed that passive emergency core cooling systems (ECCS) have a much different signature than pump-driven ECCS representative of Generation II systems. Flow behavior in Generation III systems are driven by density gradients and the passive ECCS are designed to inject over a prolonged period of time using gravitational forces as the driving head to keep the core covered and cool. Because passive systems rely on natural forces their failure probability is lower than that of pump-driven systems. Thus passive ECCS are one of the ingredients also used in Generation IV systems to ensure the system safety margin is maximized.

When passive ECCS injection begins, highly subcooled water enters horizontal piping and stratified flows of water with a density variation across the depth may occur. Because of the density variations, there are several flow features that are unseen in non-stratified single-phase flows or even shallow steam over saturated water two-phase flows. Based on the ROSA-AP600 (Japan Atomic Energy Research Institute), Liou, Schultz, and Kukita, 1997, have shown the formation of a stationary wedge, the intrusion of a heavier liquid from below, and the intrusion of a lighter liquid from above in the cold leg of a Generation III system with passive cooling for small break loss-of-coolant accidents (SBLOCAs).

Stratified flow is a subject studied mostly by civil and environmental engineers, oceanographers, meteorologists, and mathematicians. Traditionally, it has not been a focus for mechanical and nuclear engineers. As the nuclear industry enters the design stage of new generation reactors with passive systems driven solely by density gradients, stratified flows will be an important consideration.

The stratified flows encountered in open channel and oceanic settings have a free surface on which there is no shear stress and no longitudinal pressure gradient. The flow cross-section is typically rectangular or of infinite width. Stratified flows in the cold leg during passive cooling of a reactor are different in that both the shear stress and the pressure gradient are present at the upper boundary, and that the flow cross-section is circular. The knowledge of stratified flows with a free surface needs to be expanded in order to make it applicable to the passive cooling of advanced reactors.

One of the manifestations of passive ECCS are horizontal pipe runs (usually the cold legs) either filled (Case I: see Figure 1) or partially-filled (Case II: see Figure 2) with stratified water. A third condition (Case III), where the downcomer water level is below the lowest elevation of the cold leg, is also a possibility. However, Case III fluid behavior is well known and has been investigated extensively. Because the source of the passive ECCS are generally tanks filled with room-temperature water, while the reactor vessel water inventory is often near plant operational temperatures, interactions between high temperature saturated water, saturated steam, and highly 
subcooled water are virtually guaranteed. Whether the liquid behavior is Case I or Case II is dependent on a number of variables including the conditions downstream of the horizontal pipe run (in the reactor downcomer) and the passive system flow rate. Generally speaking, if the downcomer water level is above the top of the horizontal pipe section and if the passive system flow is not critical (Froude number $=1$ ) at the pipe exit, then the stratified flow condition shown in Figure 1 occurs. On the other hand, if the downcomer water level is within the diameter of the cold leg, but above the ECCS flow stream free surface in the cold leg, then the Case II condition occurs.

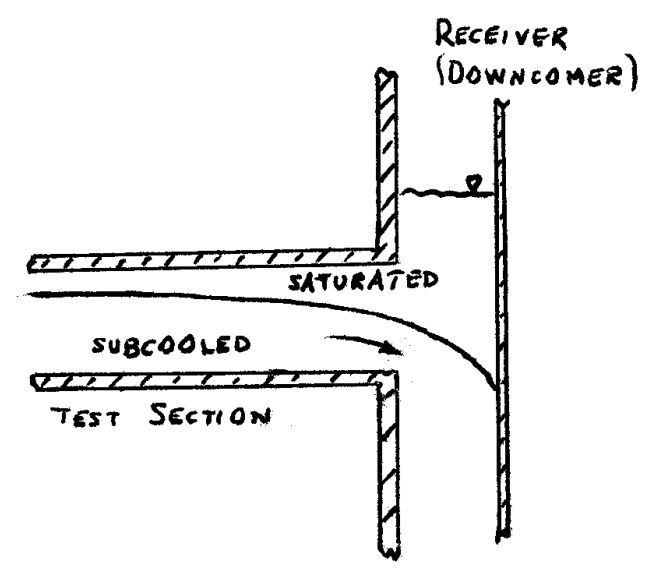

Figure 1. Case I-Downcomer water level above cold leg.

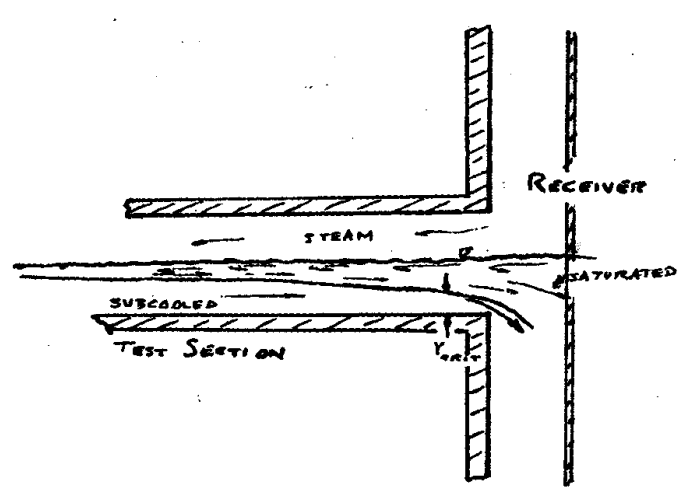

Figure 2. Case II-Downcomer water level inside cold leg

Potential problems associated with Case I and Case II flow behavior are:

a. Very large temperature gradients will be present as measured in the ROSA-AP600 experiments (see Liou, Schultz, and Kukita, 1997). The temperature gradients may easily exceed $200 \mathrm{~K}$ (gradients as large as $250 \mathrm{~K}$ have been measured) and thus lead to conditions that are conducive to thermal shock.

b. The Case II conditions, for large subcooling, are the precursors for condensation-induced water hammer (CIWH) events that may cause unexpected structural damage to the reactor system pressure boundary. Indeed, CIWH was experienced during the ROSAAP600 experiments (the ROSA-AP600 facility is a full-height, 1/30-scale simulator of the Westinghouse AP600 plant-a Generation III system) and the APEX experiments (APEX is a reduced pressure reduced height AP600 simulator located at Oregon State University) — see Yonomoto, et al, 2001.

There are ways to minimize the incursion of stratified flow into the cold leg based on design changes that lead to deeper channel depths: e.g., the mounting of low-head-loss weir walls at the cold leg discharge ${ }^{1}$. If item $b$ is of greatest importance, conceivably the passive flow behavior

\footnotetext{
${ }^{1}$ Some non-US designs presently may have such accommodations.
} 
can be designed to flow at conditions that will minimize the quantity of the subcooled liquid free surface that is available to the downcomer steam for condensation. Other potential design changes are also possibilities, e.g., lowering the cold leg with respect to the cold leg-todowncomer nozzle, etc.

To date it is the authors' opinion that considerations, such as those mentioned above, have not been included in present designs, because designers tend to consider the legs as simple conduits for transporting the fluid from point A (e.g., steam generator outlet) to point B (e.g. reactor vessel downcomer). Furthermore, channel hydraulic engineering is not taught in nuclear engineering schools. However, with the use of passive systems as essential ingredients (to meet the exceedingly high safety requirements), consideration and at least a fundamental knowledge of channel hydraulics, is essential in LWR nuclear system design.

Being able to accurately calculate the behavior of the horizontally-stratified flow from passive ECCS is quite important because:

a. The injection flow rate determines the behavior of the cold water plumes that move into the downcomer and provide cooling to the core. The movement and mixing of the cold water plumes determines whether the core is uniformly cooled or has preferential cooling at selected locations inside the core shroud. The geometry and dynamics of the pipe flow vis-à-vis the downcomer water level, with its saturated interface, are instrumental in defining the characteristics of the plume behavior.

b. Thermal gradients, imposed on the reactor system pressure boundary under various accident conditions, should be minimized.

c. The quantity of free-surface area corresponding to subcooled water will determine, in part, the importance of CIWH to the reactor design.

The Idaho State University (ISU) Nuclear Engineering Education Research (NEER) project is designed to focus on the behavior of stratified flow from the perspective of mitigating CIWH and of providing adequate data to enable mathematical models of the phenomena to be produced and to provide a basis for validation of computational fluid dynamics (CFD) software.

The following two sections describe the results of both the educational and research efforts performed at both Idaho State University and at the University of Idaho.

\section{Educational-Focused Activities:}

\section{Table Top Stratified Flow Demonstration Unit}

Efforts at the University of Idaho have led to the development of two portable, table-top stratified-flow demonstration units: an air-oil-water unit and an air-water-brine unit. Each unit can be used in the education of future nuclear engineers by providing a visual demonstration of the effects of stratified flow on a system's operation. 


\section{Development of the Air-Oil-Water Demonstration Unit}

An air-oil-water flow test loop was constructed at the hydraulics laboratory of the University Idaho. A picture in Figure 3 and a sketch in Figure 4 depict the stratified flow loop. A transparent $57.15 \mathrm{~mm}$ (2.25 inch) internal diameter and $1143 \mathrm{~mm}$ (45 inch) long acrylic pipe connects the two reservoirs. The reservoirs are filled with air, bio-diesel, and water in a layered cake fashion. The bio-diesel is essentially a food-grade rapeseed oil. At $32.2 \operatorname{deg} \mathrm{C}(90 \mathrm{deg} F)$, it has a specific gravity of 0.88 and a kinematic viscosity of 0.1 stoke. A submersible pump at the bottom of the right reservoir pumps water to the bottom inlet of the left reservoir through a $25.4 \mathrm{~mm}$ ( 1 inch) hose. The inflow is spread over the reservoir cross-section through a baffle. The water flow rate is adjustable with a control valve and measurable by a Venturi meter.

When it is desired to produce counter flows of oil and water in the pipe, another submersible pump mounted on a floating platform is immersed in the oil space of the left reservoir. It pumps the oil from the top of the left reservoir to a floating baffle at the top of the right reservoir. The baffle distributes the incoming oil over the reservoir cross-section. All water-oil, oil-air, and water-air (developed during tests) can be evenly maintained and undisturbed. The oil flow rate is adjustable by a second control valve and measurable by a second Venturi meter. Both reservoirs are open to atmosphere.

When it is desired to investigate air-oil-water flows, the floating pump and baffle units are removed. The top of the left reservoir remains open to atmosphere. The top of the right reservoir is sealed and the pressure in the air space is regulated by using a compressed air source through a control valve. The water pump recirculates water from left to right along the bottom portion of the pipe. Air is flowing from right to left through the air space along the crown of the pipe. The volumetric air flow rate is measured by a third Venturi. The size of the air gap can be varied by adjusting the liquid levels prior to starting the water pump.

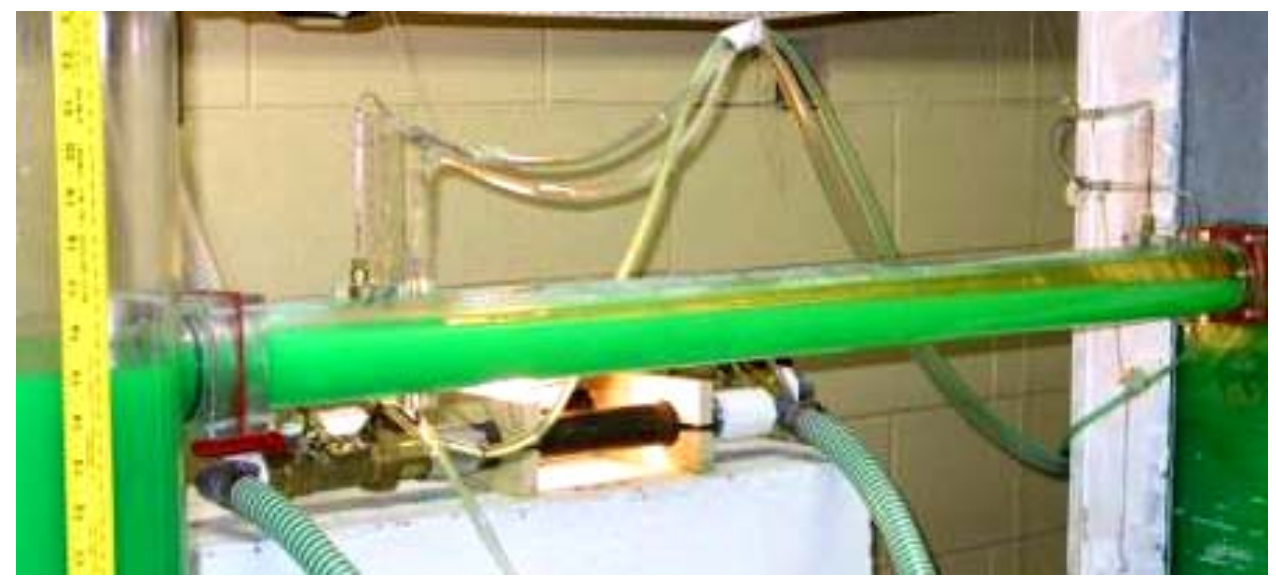

Figure 3. Photograph of the stratified flow loop. An oil wedge overlies the water flowing from left to right 


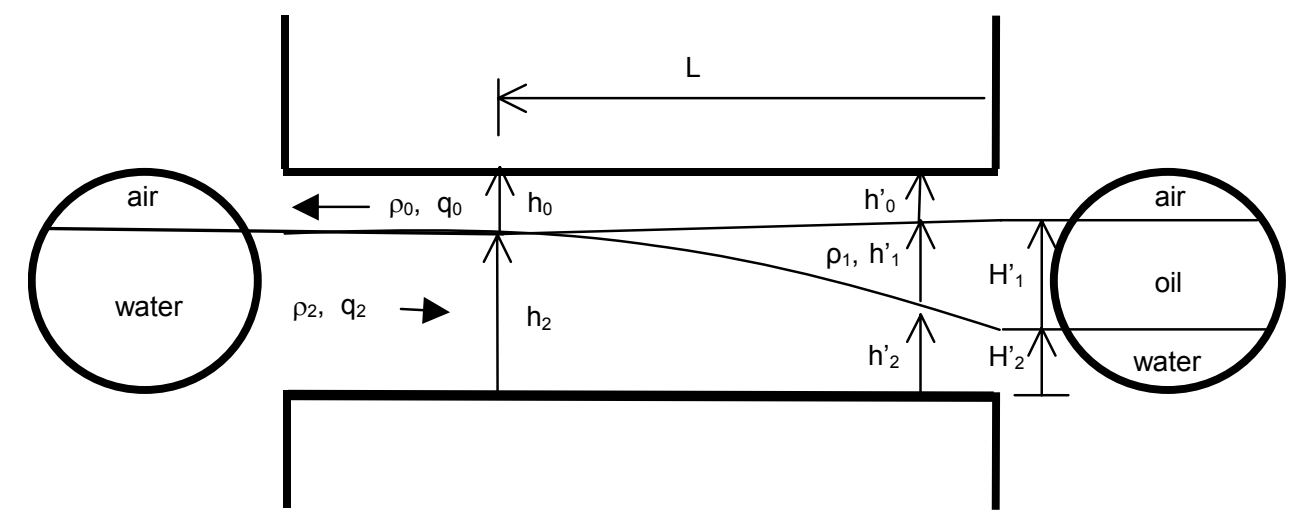

Figure 4. Schematic diagram of the stratified loop for counter flow of water and air with oil wedge formation

This test loop is used to:

1. Provide flow visualization and data for quantitative analysis in teaching stratified flow behavior relevant to reactor safety.

2. Establish the bounds of variables for stratified flow precursors to CIWH for an air-oilwater flow test loop as constructed at the hydraulics laboratory of the University of Idaho.

3. Explore the desired test conditions in preparation for extensively instrumented testing to be conducted at the Thermal Fluids Laboratory of the Idaho State University. These tests, conducted at elevated pressures and temperatures, allow condensation, vapor phase flow, and CIWH.

The relevance of the stratified flow test loop to reactor safety is explained next. Imagine the pipe as the cold leg and the right reservoir is a reactor vessel. In the mode for air-water counter flow, a portion of the water surface in the pipe is exposed to air. Had the air been steam and the water subcooled, condensation would occur over the subcooled water surface. This would induce steam flow from the reactor vessel towards the left reservoir along the crown of the cold leg. Should the steam flow be strong enough, a slug of saturated water would form and be driven rapidly toward the left. Water hammer would occur when this slug is suddenly stopped. Although condensation cannot happen in this test loop, the steam flow, mimicked by the air flow, can be estimated from the area of the exposed water surface and the extent of expected subcooling.

\section{Development of the Air-Water-Brine Demonstration Unit}

An air-water-brine flow test loop was constructed which is an improvement over the air-oilwater test loop developed and reported above. This new test loop with flow instrumentation is 
shown in Figure 5. A $38.1 \mathrm{~mm}$ (1.5 inch) internal diameter and $1143 \mathrm{~mm}$ (45 inch) long clear glass pipe connects the reservoir at left to the reservoir at right. The pipe is aligned with the horizontal by adjusting the screw-footings of the reservoirs. The left reservoir is open to atmosphere. The right reservoir has a lid. Pressurized air can be introduced into the air space to create air flow counter-current to the brine flow (described below). Prior to a test, the reservoirs are filled with water and brine in a layered-cake fashion with the brine at the bottom. The volume ratio between brine and water is about 30 to 1 . The water is colored with food dye so that the brine-water interface is visible. At a stagnant condition the brine-water interface is slightly above the centerline of the pipe and the water-air interface is slightly below the crown of the pipe.

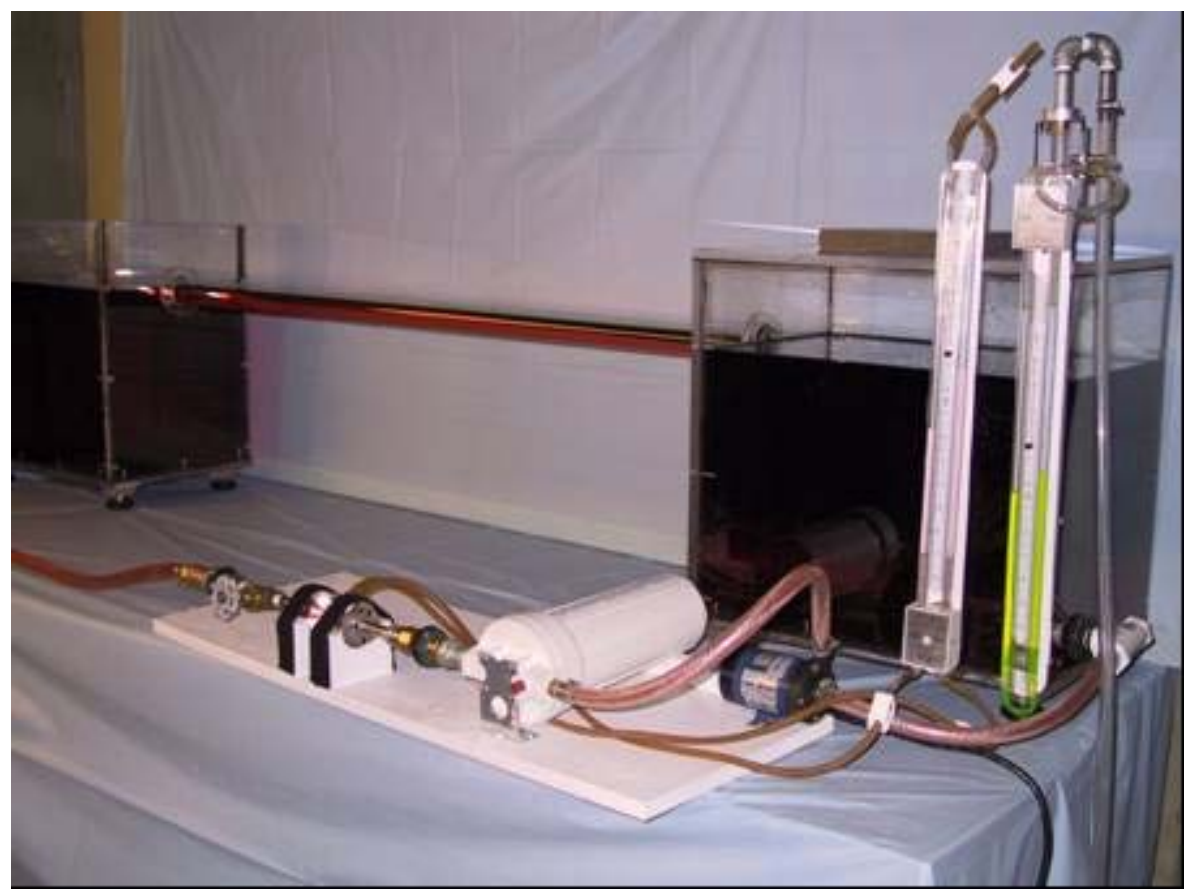

Figure 5. The portable air-water-brine system that demonstrates stratified flows

During tests, brine is pumped out from the bottom of the right reservoir and discharged to the bottom of the left reservoir. The pump is shown in the foreground of Figure 5. This pumping action sets up a head differential that drives the brine at the surface of the left reservoir to the right reservoir via the pipe. The brine flow rate is adjustable by a regulating valve so that a wedge of water with various lengths forms in the pipe. The volumetric brine flow rate is measured by a Venturi meter. The length of the wedge is measured within $25 \mathrm{~mm}(1 \mathrm{inch})$. This seemly large uncertainty is caused by two difficulties. First, the thickness of the leading edge of the wedge is too thin and hence the coloring is too faint to discern the "water's edge". Secondly, due to non-uniform transverse velocity distribution of the brine across the interface and surface tension between water and pipe wall, the "water's edge" is V-shaped. We took the bottom of the $\mathrm{V}$ as the "leading edge" of the wedge.

Because water and brine are miscible, partial mixing occurred in the right reservoir during tests. This caused the mass density of the water to increase over time. At the beginning of each test, 
the specific weight of water was determined from the weight of a fixed volume $(300 \mathrm{cc})$ of water collected at the surface of the right reservoir. Weights were measured by a balance scale with a resolution of 0.1 gram. The uncertainty in the calculated specific weight is estimated to be less than 0.05 percent.

The positions of the brine-water and water-air interfaces in the pipe were measured by aligning a dial-micrometer against the pipe. In each reading, the line of sight is nearly horizontal. The resolution of the micrometer is $0.0025 \mathrm{~cm}(0.001 \mathrm{inch})$ but the uncertainty in the interface position is estimated at $0.01 \mathrm{~cm}(0.005 \mathrm{inch})$.

\section{Education and Training of Graduate Students}

The water-steam two-phase flow loop (TPFL), described later in this report, provided the basis for two Ph.D. dissertations at Idaho State University. Both dissertations are currently in progress. The first candidate, Hiral Kadakia, was the Ph.D. fellow supported by this NEER project and his dissertation topic focuses on the experimental development and capabilities of the system. His proposed title is "Stratified Two-Phase Flow Experimentation for Innovative Improvements in Advanced LWR Passive Safety System Design."

The second candidate, Richard Schultz, has been a collaborative INL researcher on this project in addition to his work on his Ph.D. His dissertation topic focuses on the modeling of the observed phenomena and has the proposed title "Techniques to Model a Typical Condensation-Induced Water Hammer Event Measured at the Two-Phase Flow Test Facility (TPTF)."

In addition, the TPFL will be used as an experimental apparatus for graduate education in two phased flow, horizontal stratified flow, and steam-water interactions.

\section{Research-Focused Activities:}

\section{Steam-Water Two Phase Flow Loop}

A steam-water two-phase flow loop has been designed and constructed at the Skyline Laboratory at Idaho State University. This loop became operational in January 2006 with startup testing from January to April of 2006. The first test with data was performed on April 12, 2006. Since this first date, the operation of the TPFL has been refined in order to provide required parameters and produce the desired phenomena.

A schematic of the TPFL is shown in Figure 6 (a landscape view of this schematic can be found in the appendix). Water is pumped via the hot loop pump through loop heaters which in turn heat the water to a saturation condition. Steam is formed by controlled expansion of this saturated water through a valve into the simulated reactor vessel. This steam provides the counter-current vapor flow in the horizontal test section (described below).

Subcooled cold water is provided by either pumping water via the cold loop pump, through a loop cooler heat exchanger, and into the horizontal test section or by adding water directly to the cold leg from a treated city water source. 


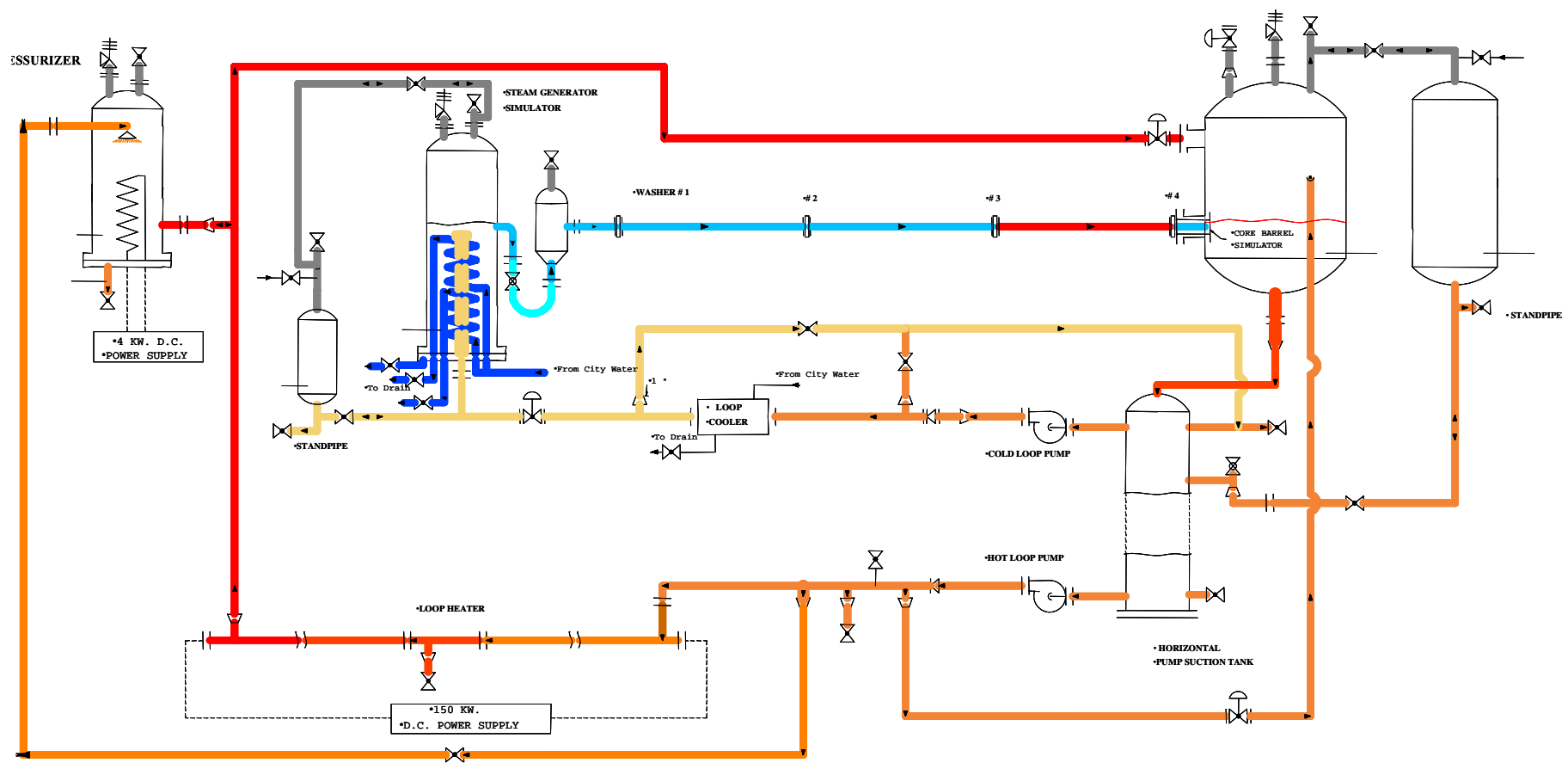

Figure 6. Schematic diagram of the steam-water two phase flow loop at the Skyline Lab at Idaho State University.

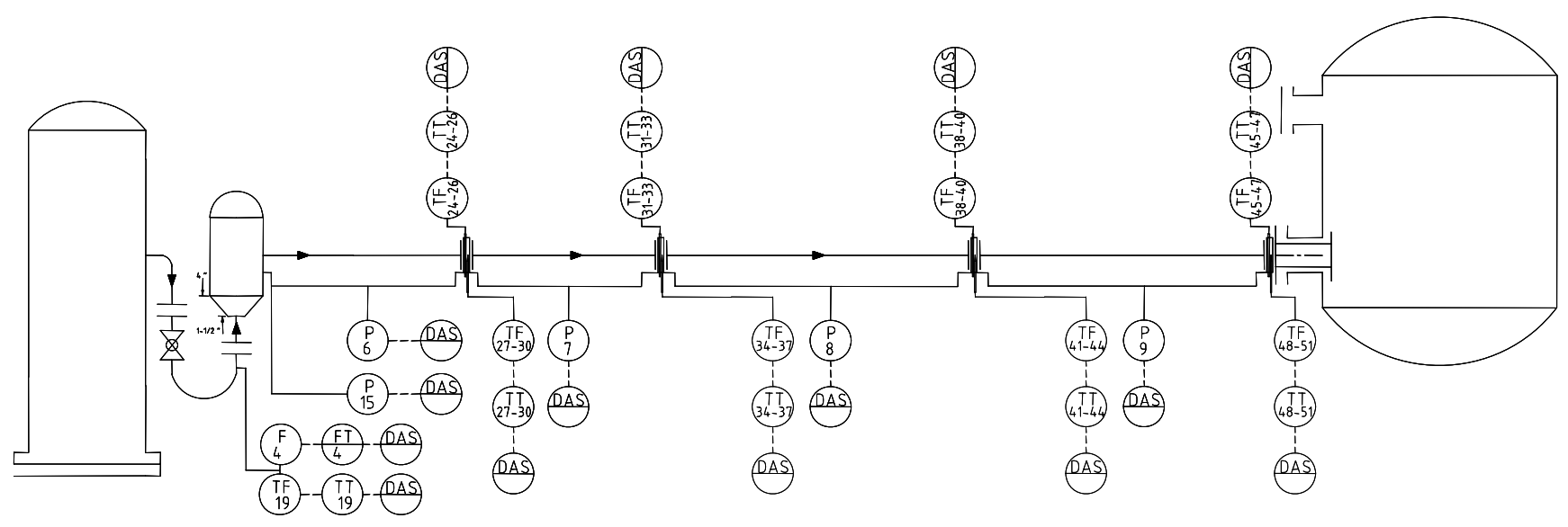

Figure 7. Schematic diagram of the horizontal test section of the TPFL.

Figure 7 shows a schematic of the horizontal test section. Cold water enters the test section from the left (opposite the simulated reactor vessel) and flows to the right. In most test configurations, the test section was half-full of liquid water (void fraction of 50\%). Steam enters the test section from the right (exits from the reactor vessel) and flow to the left, thus creating a counter-current flow situation. In addition, inside the reactor vessel, steam has been condensing and forming a saturated liquid water layer on top of the subcooled water. This saturation layer exits the reactor 
vessel and protrudes into the horizontal test section, thus forming a stratified liquid situation. Figure 8 shows a sketch of the stratified flow condition including the counter-flowing steam.

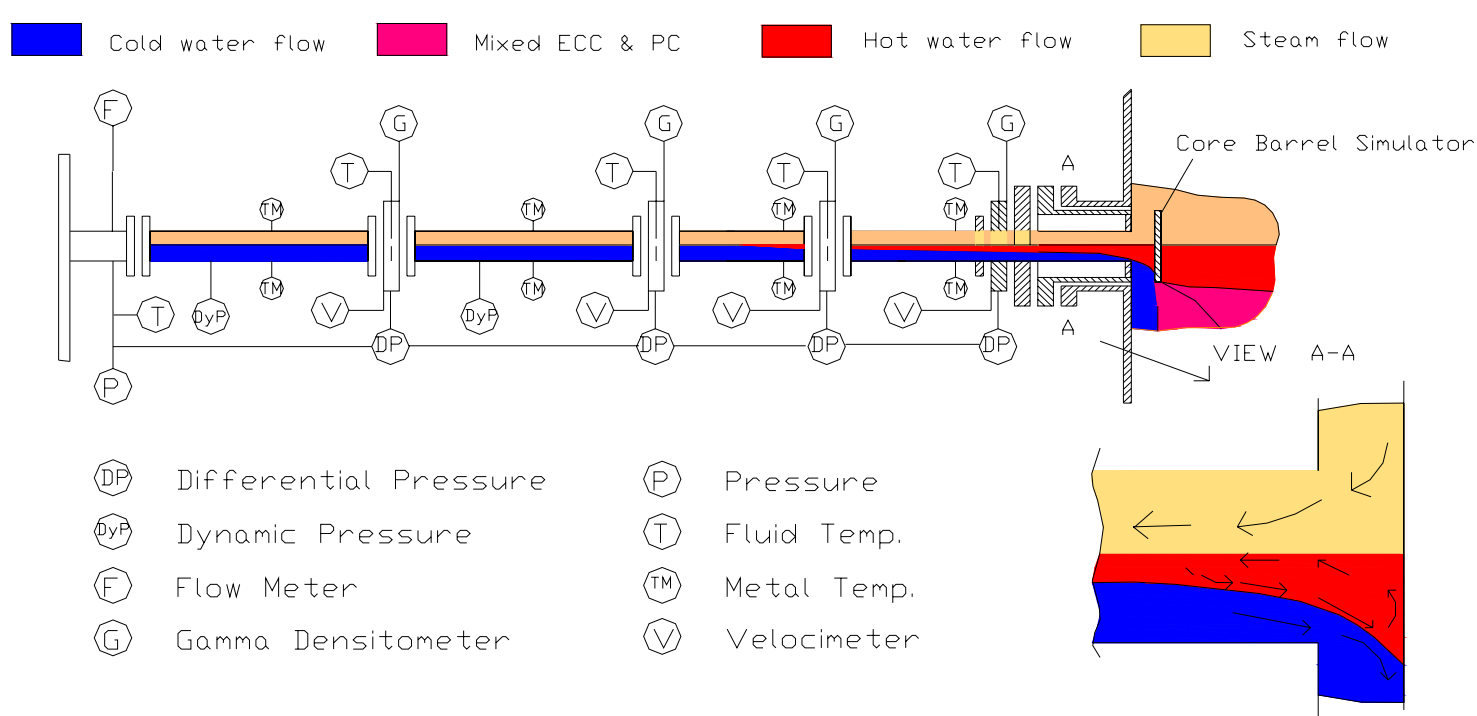

Figure 8. Test section with stratified flow: subcooled water flowing to right covered with saturated water and steam.

In order to observe the mixing of the saturated and subcooled layers and the development of unstable wave formations, it was decided to make the horizontal test section transparent. Glass test sections were purchased from QVF/De Dietrich in lengths of $100 \mathrm{~mm}, 200 \mathrm{~mm}$, and 400 $\mathrm{mm}$. The initial testing arrangement consists of (starting at the simulated reactor vessel) instrument washer, $200 \mathrm{~mm}$ glass section, instrument washer, $200 \mathrm{~mm}$ glass section, instrument washer, $100 \mathrm{~mm}$ glass section, instrument washer, and a $100 \mathrm{~mm}$ glass section (see Figure 9). In order to accommodate axial thermal expansion and its impact on the integrity of the glass sections, a bellows was inserted between the glass and steel pipe sections (see Figure 10). The glass test sections were hydrostatically tested to ensure their reliability during testing conditions. As a result of the glass test sections, the operating pressure of the TPFL was limited to approximately 5 psig.

A video system was installed and used to remotely control the TPFL as well as record any visual observations during testing. Timing was developed in order to synchronize the video timing with the data from the data acquisition system (DAQ). Remote operation was desirable in order to minimize personnel's exposure to potentially hazardous situations. 


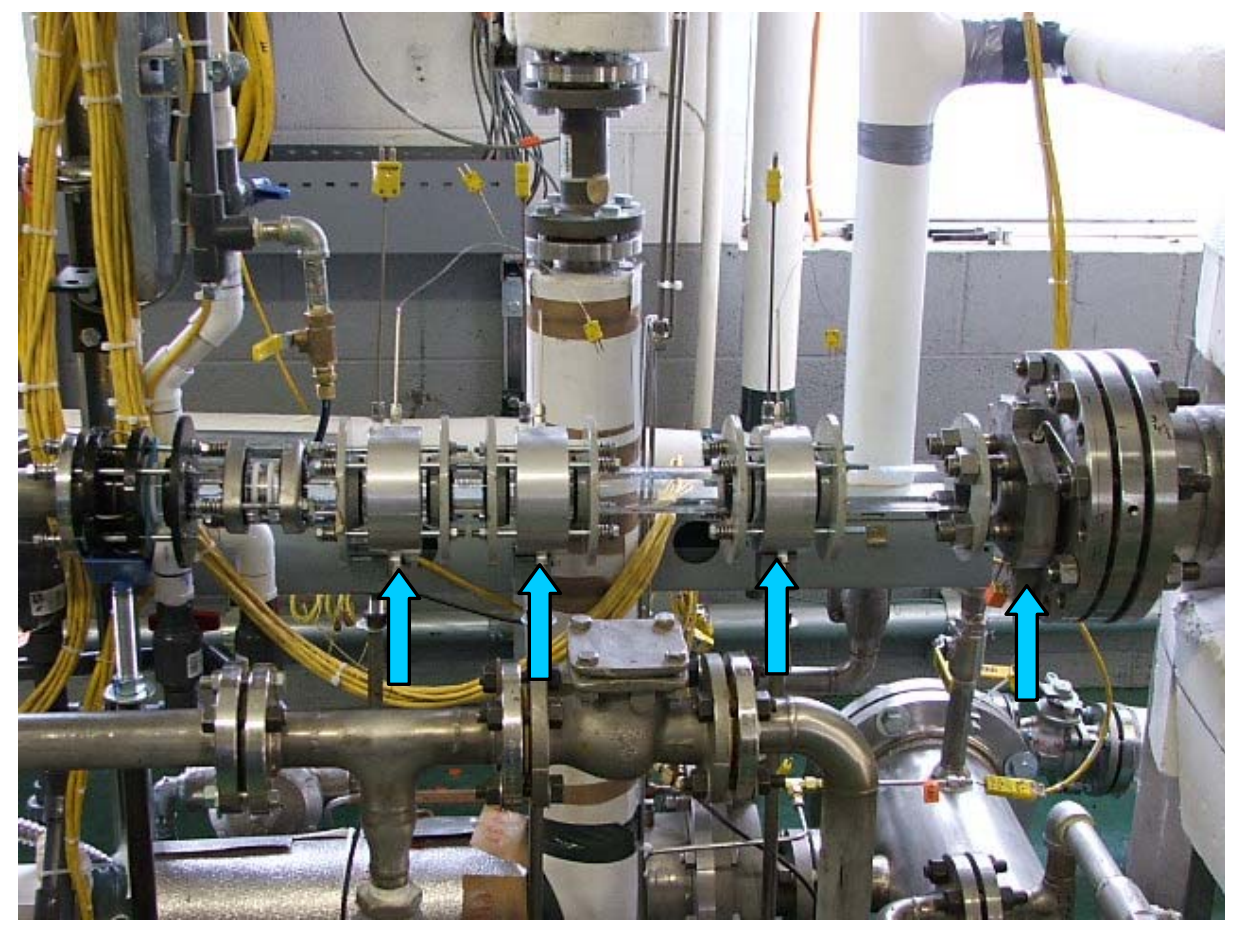

Figure 9. Photograph of the glass test section installed in the flow loop. Arrows indicate the location of the instrumented washers. The washer on the far right of the picture is closest to the simulated reactor vessel and contains accommodations for a gamma ray densitometer.

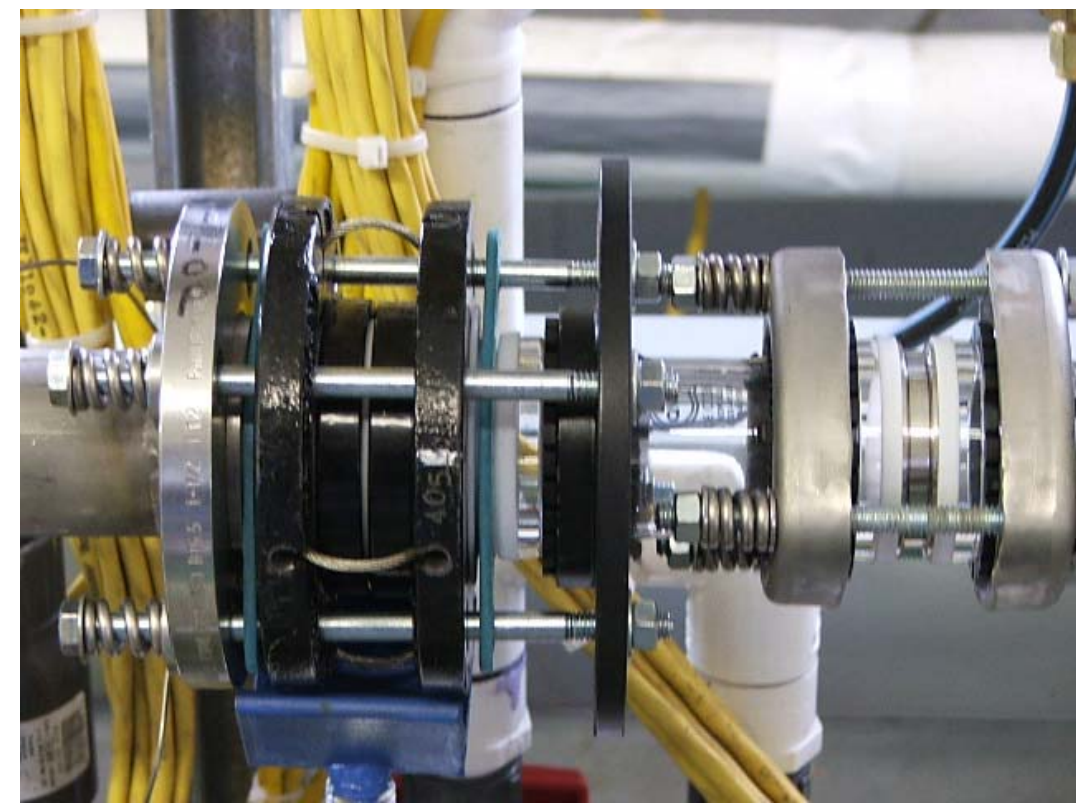

Figure 10. Photograph of the bellows unit separating the glass and steel pipe sections. 
Instrumentation installed in the TPFL consists of:

- 22 pressure transducers (includes 3 high-frequency and 5 level sensors)

- 2 low-flow thermal anemometers (using 4 TC's each)

- 43 thermocouples

- 7 flow meters

All data are recorded via computers using National Instrument's LabView software. In addition, a particle tracking velocimeter (PTV) system is being installed in the loop for calibration activities and a particle imaging velocimeter (PIV) system is under construction at the ISU College of Engineering's Measurement and Control Engineering Research Center (MCERC).

Figures $11-13$ are photographs depicting various aspects of the TPFL.

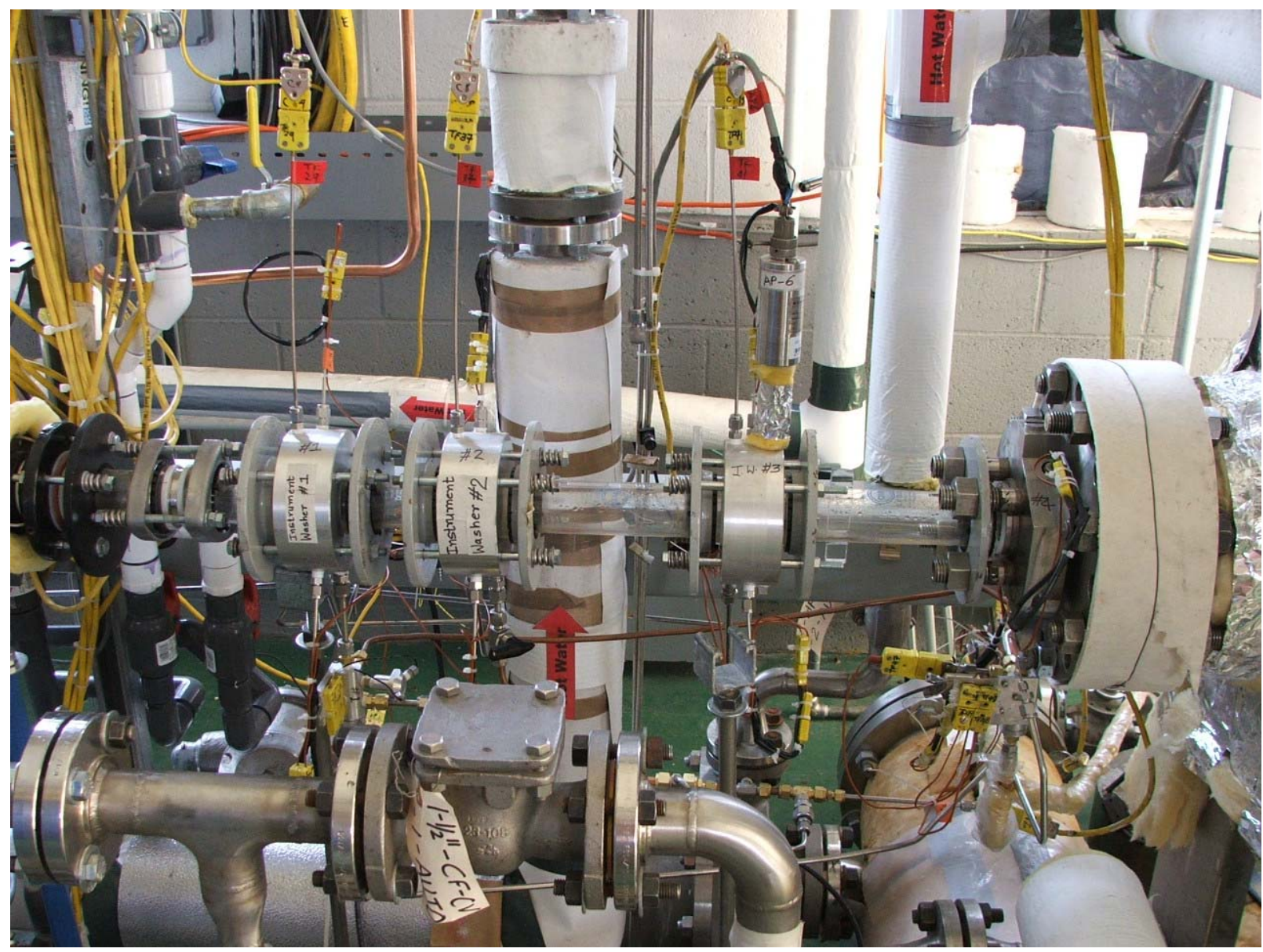

Figure 11. Photograph of the glass horizontal test section showing instrumentation installed. 


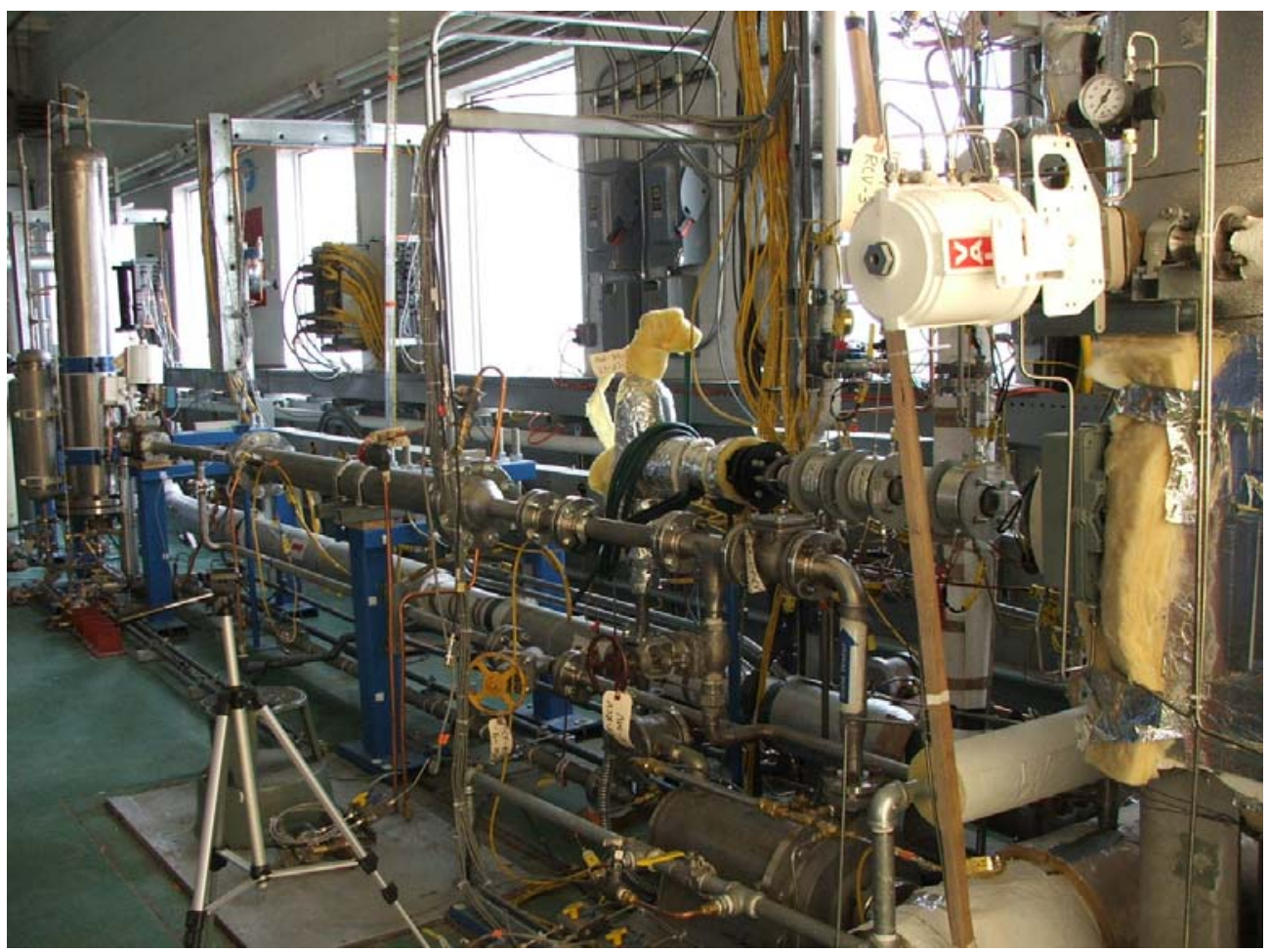

Figure 12. Photograph of the TPFL, taken near the simulated reactor vessel, and looking towards the simulated steam generator.

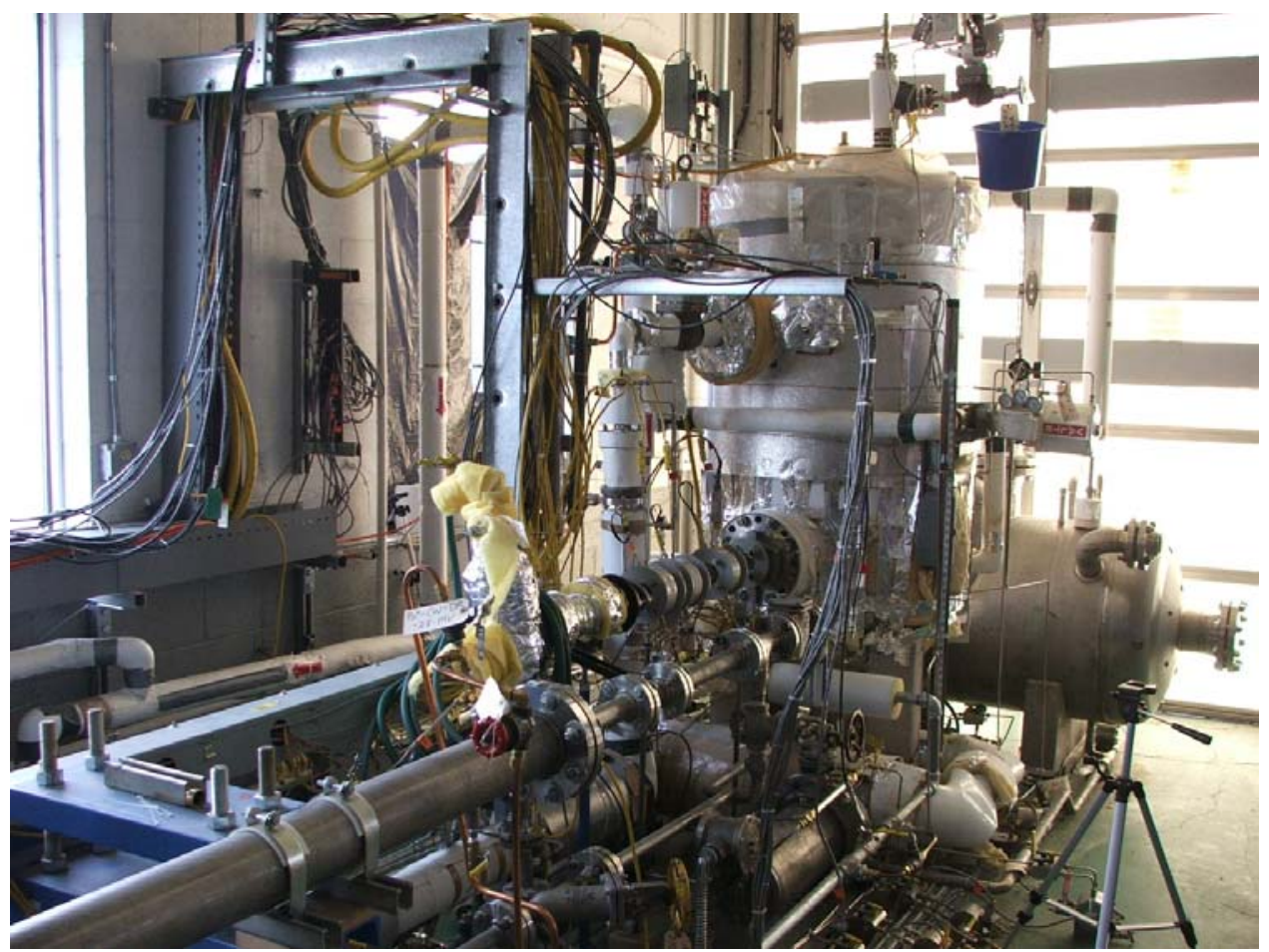

Figure 13. Photograph of the TPFL showing the horizontal test section connection to the simulated reactor vessel. 


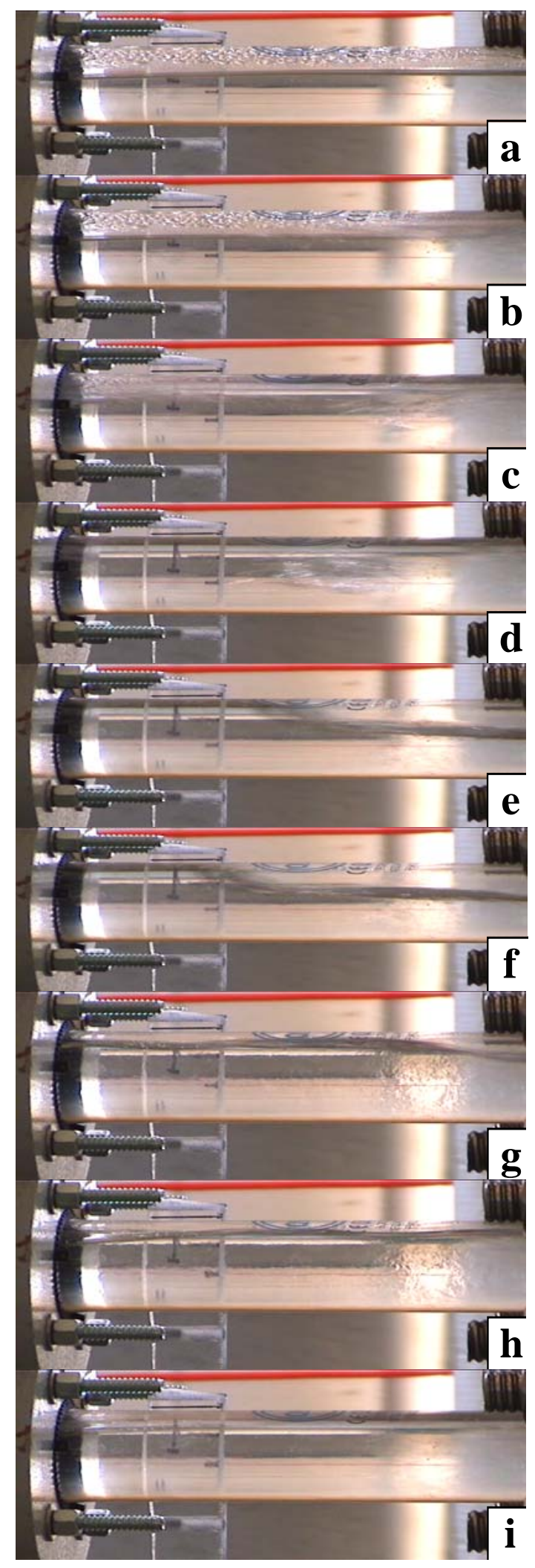

Figure 14. Still-shot segments from representative video during TPFL tesing. 
Figure 14 shows a representative segment of still-shots from video taken during testing. In these photographs, the initial condition for the horizontal test section is approximately $50 \%$ liquid and $50 \%$ steam (a). The counter-current flow condition causes a wave to bridge the steam-gap in the pipe (b) and a water hammer is initiated (c). Note in (d) the highly turbulent conditions existing during the water hammer event. As the water hammer wave passes through the video camera's filed of view (e \& f), it rebounds on the far wall and returns in the opposite direction (g-i).

A pure condensation-induced water hammer event is never achieved because the horizontal section contains a small quantity of non-condensable gases (air). The air acts as a spring to dampen the wave and absorb energy, thus reducing the chance for extreme pressure spikes that could potentially rupture the loop's piping.

Figure 15 shows a close-up of another still-shot segment from testing video footage. As observed in this series of photographs, a wave develops and then bridges the gap, thus inducing the water hammer event.

Figure 16 shows a representative plot of temperature versus time for a water hammer event during testing. The shape of this plot is typical to that observed in the rest of the testing. TF42, TF43, and TF44 represent thermocouple temperature sensors at various radial positions, contained within a rake. The top value (TF42) is in the top section of the pipe and would be exposed to pure steam in a quiescent condition and 50\% void fraction. The middle value (TF43) is located in the center of the pipe and is usually covered with liquid water. Finally, the lower value (TF44) is located in the bottom section of the pipe flow and is almost always exposed to subcooled water. This temperature rake is immobile (i.e. constant radial positions) and located in an instrument washer (refer to Figure 9). Each of the four instrument washers contains a 3temperature sensor rake.

In Figure 16, it can be noted that three water hammer events, and their consequent waves, are observed in the data: the first at approximately 4 seconds, the second at approximately 9 seconds, and the third at approximately 13 seconds. During a water hammer event, a liquid wave fills the entire pipe at a given cross-sectional location, as observed in Figures 14 and 15. As a result, all three temperature sensors in a rake are exposed to liquid water, and thus, their recorded temperatures will approach one another. As the wave passes and steam is again present at this particular cross-section, the top temperature sensor (TF42) is exposed to the steam and its temperature increases back to its initial value (from approximately $60{ }^{\circ} \mathrm{C}$ when submerged in liquid water to approximately $95^{\circ} \mathrm{C}$ in the steam - note: this testing was performed at approximately 5 psig operational pressure and the TPFL is locate in Idaho Falls, Idaho, at an elevation of $4700 \mathrm{ft}$ above sea level). It can also be noted that there is a time delay effect at the beginning of each re-exposure to steam due to the time constant of the thermocouple and the drying and/or removal of water droplets from the sensor. 

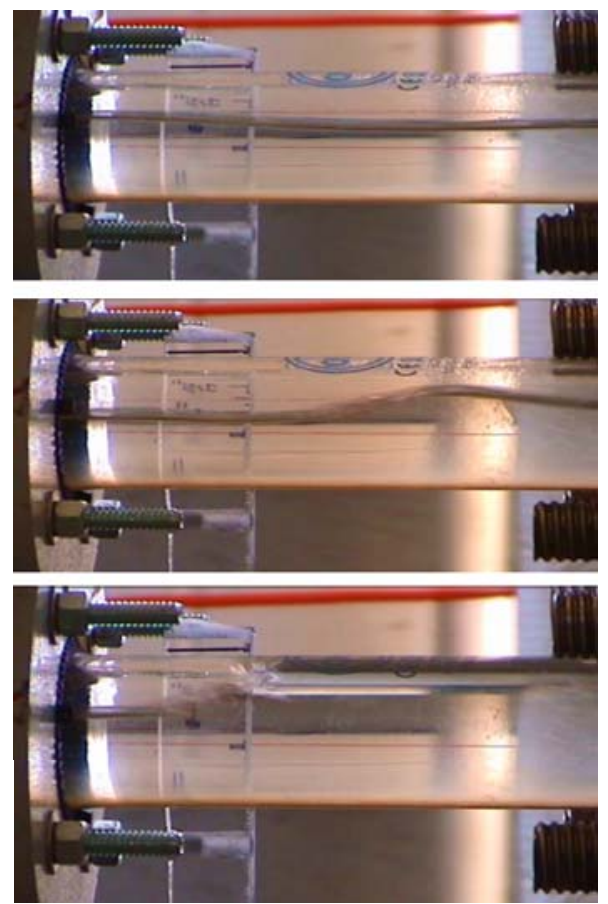

Figure 15. Close-up of another still-shot segment from TPFL test video.

\section{Temperature v/s Time during Water Hammer}

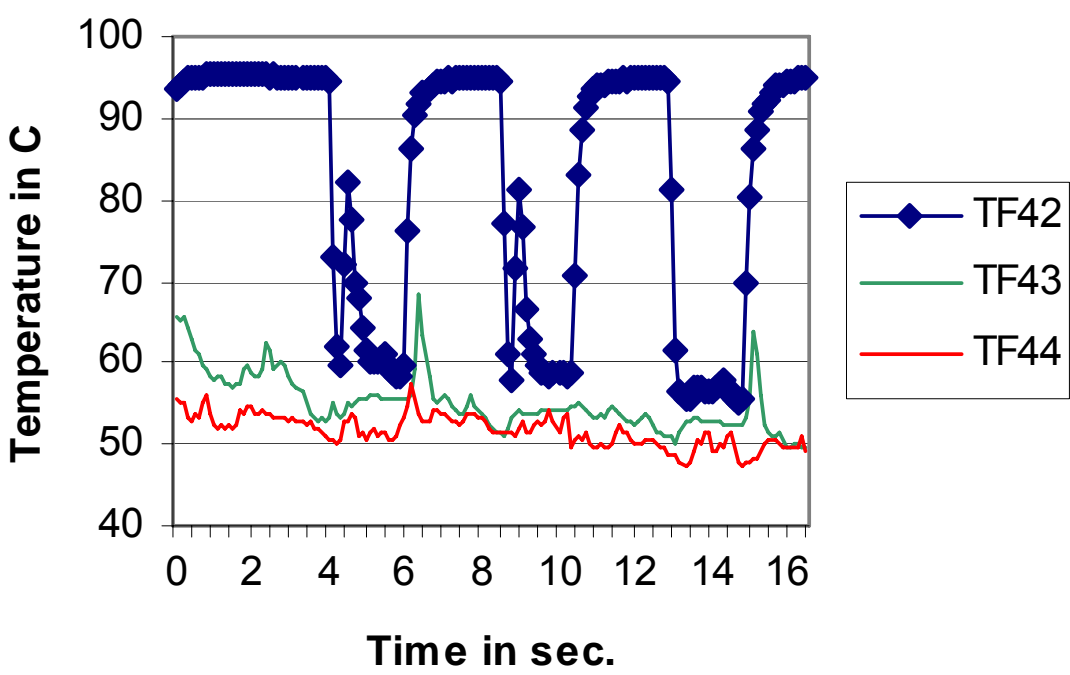

Figure 16. Representative temperature versus time data for TPFL testing.

Also, during the water hammer event, it can be observed from Figure 16 that the middle temperature sensor (TF43) becomes briefly exposed to steam after the first and third water hammer waves. This is evident by the sharp spike in data for TF43, occurring at approximately 6.5 and 15 seconds. In Figure 14, segments e \& $\mathrm{f}$ (still-shots of the back edge of the water hammer wave), it is observed that the liquid water level as the wave passes by is less than that before the wave occurred (segment a). As a result, a temperature sensor in a lower location may be exposed to pure steam (sensor TF43 for this case).

The uncertainty of the temperature measurement data was calculated to be approximately $0.56 \%$. The difference between temperature readings of TF43 and TF44, as shown in Figure 16 before the first water hammer wave (time less than 4 seconds), exceeds this uncertainty value. Therefore, it is postulated that what is being observed is the temperature stratification of the liquid water. A void fraction slightly greater than $50 \%$ would place the location of TF43 at slightly below the steam-liquid interface. At the interface, steam is condensing onto the subcooled layer, forming a warmer liquid layer. Further, the newly condensed water is being cooled by the much larger mass of subcooled liquid. In addition, for locations near the simulated reactor vessel, a saturated wedge layer is formed and protrudes as a tongue into the horizontal test section. Hence, the TF43 temperature sensor is exposed to this warmer liquid layer as compared to the TF44 temperature sensor located well within the subcooled layer.

Note in Figure 16 that after the first water hammer wave passes (approximately 6 seconds), the temperature of both TF43 and TF44 (the middle and bottom temperature sensors, respectively), are approximately equal within the uncertainty of the measurements. This is a result of the 
extremely turbulent flow conditions produced by the passage of the water hammer wave. This turbulent motion can be observed thermal-induced diffraction in segments $\mathrm{c}$ through $\mathrm{h}$ of Figure 14.

\section{Table Top Stratified Flow Demonstration Unit - Data and Analysis}

In the second project year, we constructed a second portable stratified flow demonstration unit, conducted tests demonstrating different extent of intrusion of the lighter fluid, and analyzed the observed flows based on the first principles of fluid mechanics. All these accomplishments contribute toward our objective of providing a demonstration apparatus and instructional material for teaching stratified flows to nuclear engineers.

\section{Representative Test Data}

The data for three representative tests are shown in Table 1. Photographs of the interface for these tests are shown in Figure 17.

In Table $1, \mathrm{H} 2 u=$ depth of the brine flow at the leading edge of the wedge, $\mathrm{H} 1 d=$ thickness of water layer measured downstream, $\mathrm{H} 2 d=$ thickness of the brine layer measured downstream, and $L=$ length between the leading edge and the downstream measurement station. Figure 17 shows the stationary wedge for these tests. The interface between the water and the brine is sharp and without any interfacial mixing. For tests with high brine flow rates, the interface becomes wavy at the downstream end of the tube where the velocity of the brine is the highest. Driven by the brine flow, water circulates inside the stationary wedge but there the net water flow is zero at any cross-section.

Table 1. Representative Test Data from Demonstration Unit

\begin{tabular}{|c|c|c|c|c|c|c|c|}
\hline & $\gamma_{1} \mathrm{~N} / \mathrm{m}^{3}$ & $\Gamma_{2}, \mathrm{~N} / \mathrm{m}^{3}$ & $Q, 10^{-6} \mathrm{~m}^{3} / \mathrm{s}$ & $H 2 u, \mathrm{~cm}$ & $H 1 d, \mathrm{~cm}$ & $H 2 d, \mathrm{~cm}$ & $L ., \mathrm{cm}$ \\
\hline Test A & 10252 & 11091 & 23.9 & 2.45 & 0.98 & 1.55 & 85 \\
\hline Test B & 10501 & 11091 & 26.5 & 2.16 & 0.81 & 1.56 & 18 \\
\hline Test C & 10725 & 11091 & 17.7 & 1.80 & 0.30 & 1.58 & 5 \\
\hline
\end{tabular}




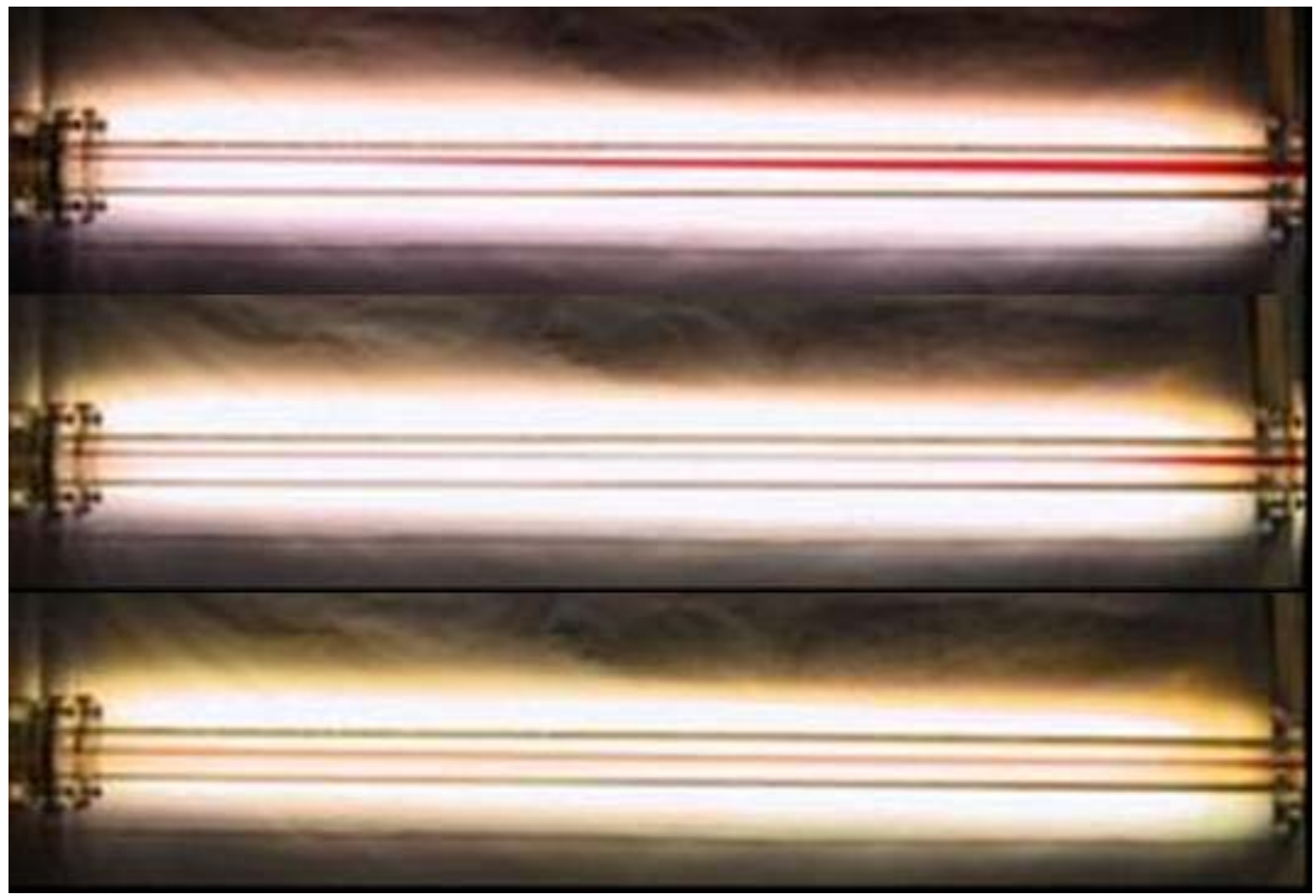

Figure 17. Pictures of the stationary wedge (fresh water dyed red) overlying brine flow(clear). Top: test A. Middle: test B, Bottom: test C. The glass pipe has an outside diameter of $4.69 \mathrm{~cm}$. The pipe length between inlet and outlet flanges is $109 \mathrm{~cm}$. The downstream measurement station (see Table 1) is at the face of the outlet flange. The pipe exit is $5.72 \mathrm{~cm}$ beyond the outlet flange. The wedge starts at 24, 91, and $104 \mathrm{~cm}$ from the inlet flange for test A, B, and C, respectively. For each case, the red streak before the wedge is caused by surface tension

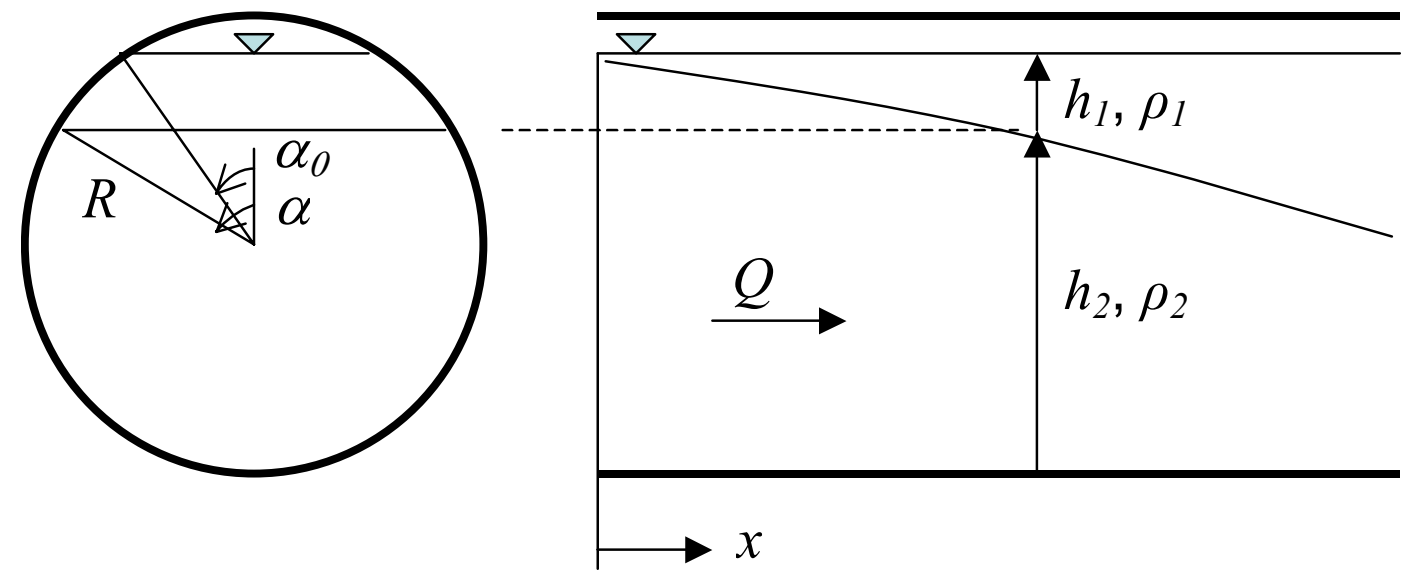

Figure 18. Cross-section and longitudinal profile of a stationary wedge 


\section{Analysis}

The cross-section and longitudinal profile of the wedge is shown schematically in Figure 18 where $\alpha_{0}=$ angular position of the water-air interface, $\alpha=$ angular position of the brine-water interface, $Q=$ brine flow rate, $h_{1}=$ thickness of water layer, $h_{2}=$ thickness of brine layer, $\rho_{1}=$ mass density of water, $\rho_{2}=$ mass density of brine, $x=$ distance coordinate starting at the leading edge of the wedge where $\alpha=\alpha_{0}$. Based on observations, we assume that there is no interfacial mixing and that hydrostatic condition exists in the vertical direction. By applying the momentum conservation principle, we obtained an analytical expression for the shape of the interface shown below as Equation 1:

$$
x=-\int_{\alpha_{0}^{*}}^{\alpha} \frac{\frac{\partial}{\partial \alpha}\left(F_{1}+F_{2}+M\right) d \alpha}{S_{b}+S_{i}\left(1-\frac{\pi-\alpha+\frac{\sin 2 \alpha}{2}}{\alpha_{0}-\alpha-\frac{\sin 2 \alpha_{0}-\sin 2 \alpha}{2}}\right)}
$$

In Equation $1, F_{1}=$ hydrostatic force on the lighter liquid, $F_{2}=$ hydrostatic force on the heavier liquid, $M=$ momentum flux of the brine, $S_{b}=$ shear force per unit length between liquid and pipe wall, and $S_{i}=$ shear force per unit length at the interface of the liquids. These quantities are defined below in Equations 2 through 6:

$$
\begin{gathered}
F_{1}=\gamma_{1} R^{3}\left\{\cos \alpha_{0}\left[\alpha-\alpha_{0}-\frac{\sin 2 \alpha-\sin 2 \alpha_{0}}{2}\right]-\frac{2}{3}\left(\sin ^{3} \alpha-\sin ^{3} \alpha_{0}\right)\right\} \\
F_{2}=\gamma_{2} R^{3}\left\{\left[\frac{\gamma_{1}}{\gamma_{2}}\left(\cos \alpha_{0}-\cos \alpha\right)+\cos \alpha\right]\left(\pi-\alpha+\frac{\sin 2 \alpha}{2}\right)+\frac{2 \sin ^{3} \alpha}{3}\right\} \\
M=\frac{\rho_{2} Q^{2}}{A} \\
S_{b}=\frac{\rho_{2} f}{8}\left(\frac{Q}{A}\right)^{2}[2(\pi-\alpha) R] \\
S_{i}=\frac{0.664}{\sqrt{\operatorname{Re}_{x}}} \rho_{2} \frac{U^{2}}{2}(2 R \sin \alpha)
\end{gathered}
$$

In these equations, $A=$ flow cross-sectional area of brine, $\gamma_{1}=$ specific weight of water, $\gamma_{2}=$ specific weight of brine, $f=$ Darcy-Weisbach friction factor, $R e_{x}=$ Reynolds number based on 
leading edge distance, and $U=$ average velocity of brine. Details can be found in Liou, et al, 2005.

The integrand in Equation 1 is a function of both $\alpha_{0}$ and $\alpha$. However, since $\alpha_{0}$ varies much slower than that of $\alpha$, the integral is evaluated numerically by holding the $\alpha_{0}$ in the integrand to $\alpha_{0}{ }^{*}$. Figure 19 shows a comparison between the measured and the calculated wedge lengths. It is seen that Equation 1 can predict the intrusion length reasonably well.

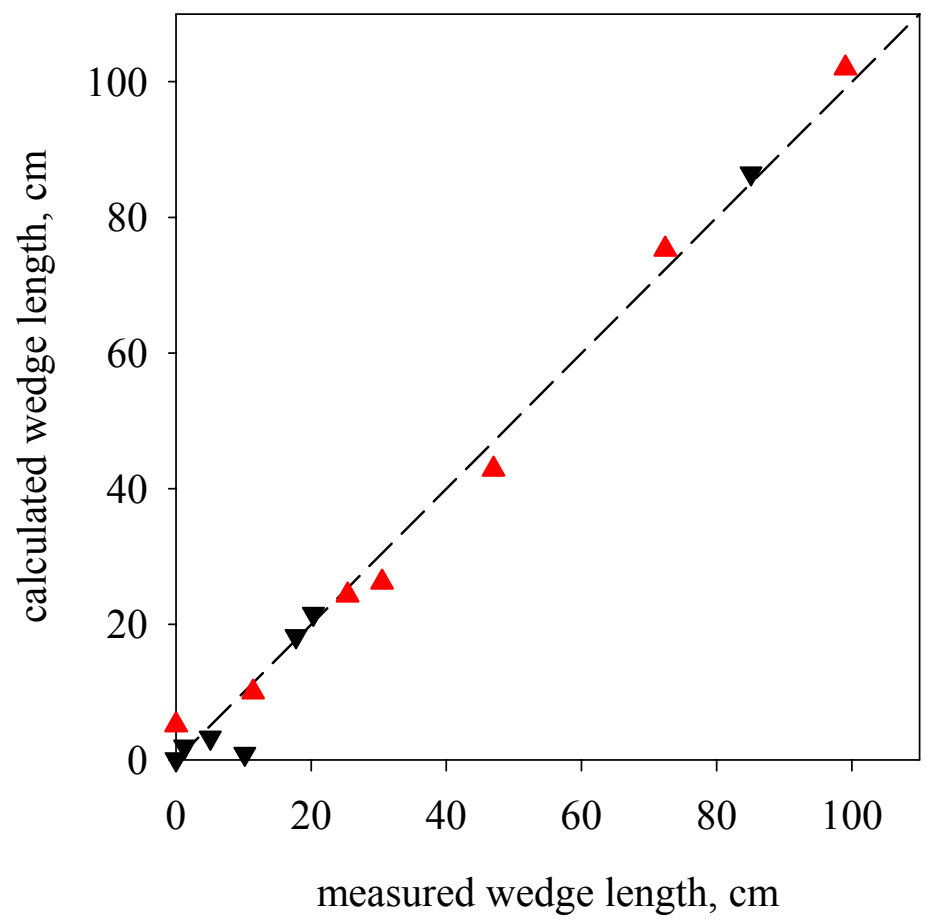

Figure 19. A comparison of measured versus computed wedge length. The symbols represent data from two test series

Next, we establish the sufficient condition for preventing the intrusion of a lighter fluid against the flow of a heavier fluid in a conduit. Consider the ratio in the bracket of the denominator of the integrand in Equation 1. The numerator of is positive for $\alpha$ between 0 and $\pi$ (which is true by definition). The denominator of this ratio is negative for $\alpha_{0}$ less than $\alpha$ and $\alpha$ between 0 and $\pi$ (which are also true by definition). Thus, the denominator of the integrand is always positive. This then requires the numerator of the integrand to be negative to have any wedge length. In other words, for a wedge of any length to exist, the numerator of the integrand must be negative. The limiting case for a wedge to "just" form is

$$
\frac{\partial}{\partial \alpha}\left(F_{1}+F_{2}+M\right)=0
$$


Using Equations 2, 3, and 4 and carrying out the derivatives, Equation 7 reduces to

$$
\left(F^{\prime}\right)^{2}=\frac{Q^{2}(2 R \sin \alpha)}{g^{\prime}\left(R^{2}\left(\pi-\alpha+\frac{\sin 2 \alpha}{2}\right)\right)^{3}}=1
$$

where

$$
g^{\prime}=\frac{\gamma_{2}-\gamma_{1}}{\gamma_{2}} g
$$

represents the reduced gravitational acceleration resulting from the buoyancy provided by the lighter fluid (water in the present case). In Equation 8, $2 R \sin (\alpha)$ is the width of the brine surface and the $R^{2}(\pi-\alpha+\sin (2 \alpha) / 2$ is the brine flow area. The square root of ratio in Equation 8 is a densimetric Froude number which indicates the relative magnitude of inertia and reduced gravity forces. If the inertia force exceeds the gravity force $\left(F^{\prime} \geq 1\right)$, the lighter fluid cannot intrude into the conduit. Otherwise, intrusion occurs and the extent of intrusion depends on the magnitude of $F$ '. This feature of the stratified flow is demonstrated by our test apparatus. Figure 20 shows the results. In Figure 21, $Q^{2} / g^{\prime} R^{5}$ is plotted against $\alpha$. Flows that prevent intrusion are represented by points above the curve.

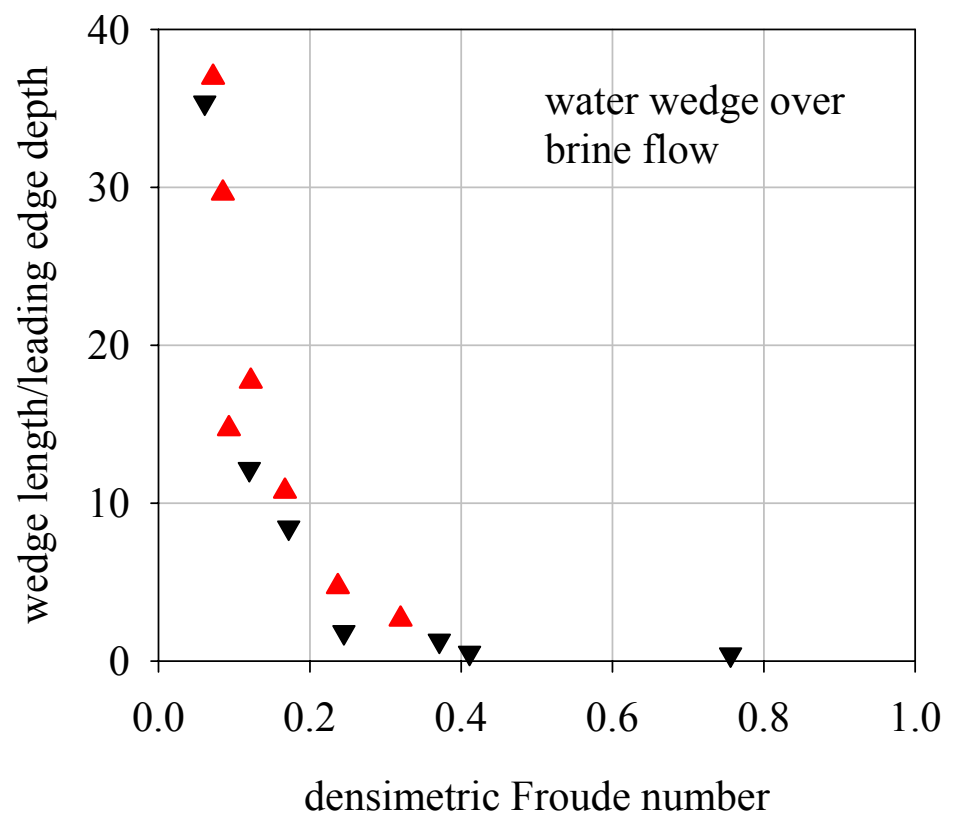

Figure 20. Scaled wedge length as a function of densimetric Froude number from two series of tests. 


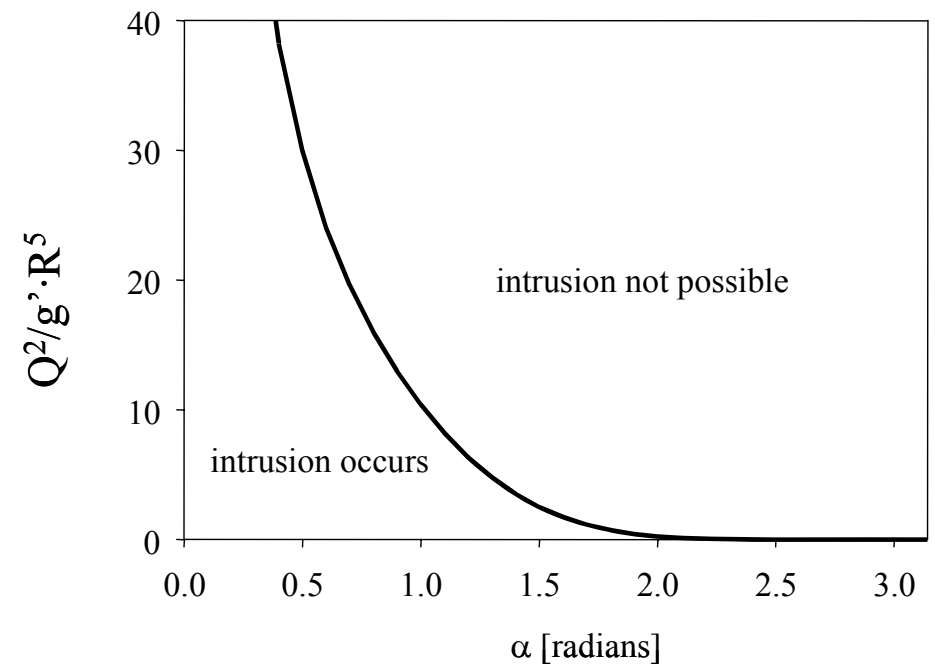

Figure 21. Flows where intrusion is not possible (above the curve) are separated from those where intrusion always occur

\section{Summary of Accomplishments:}

A steam-water two phase flow loop has been designed, fabricated, commissioned, and is in operation at the Skyline Laboratory at Idaho State University. This loop contains a transparent horizontal test section to investigate two phase flow, stratified flow, and steam-water interactions. This loop is fully instrumented, remotely operated, and has the capability to visual record observed phenomena.

The ISU steam-water TPFL provides a basis of data to correlate observed physical phenomena, as seen during loop testing, to the results of computer code models (such as RELAP). From these data, a map can be constructed depicting the operational envelope, and corresponding conditions, needed to initiate a water hammer event.

Portable, table-top air-oil-water and air-water-brine demonstration units have been designed, fabricated, and are in operation at the University of Idaho. These loops provide a visual tool to assist in the education of nuclear engineering students in understanding stratified flow conditions that might impact reactor designs. In addition, mechanistic models based on fundamental principles have been used in conjunction from data taken from these loops to describe the phenomenon of stratified layer intrusion in horizontal flow conditions. Also, information learned from these loops was instrumental in the design of the larger TPFL at Idaho State University.

This research has been the basis for two Ph.D. dissertations at Idaho State University. One of these Ph.D. students was funded for three years under the NEER grant. 


\section{Acknowledgements:}

This report is based upon work supported by the U. S. Department of Energy under Award Number DE-FG07-03ID14500.

\section{References:}

Liou, C. P., Schultz, R. R., and Kukita, Y., 1997, "Stably Stratified Flows in Closed Conduits," ICONE5-2-24, Proceedings of the $5^{\text {th }}$ International Conference on Nuclear Engineering, ASME/SFEN/JSME, May, Nice, France.

Liou, Jim C. P., Donald L. Parks, Richard R. Schultz, and Brian G. Williams, 2005, "Stratified Flows in Horizontal Piping Systems of Passive Emergency Core Cooling Systems," presented at the International Conference on Nuclear Engineering (ICONE13), May 16-20, Beijing, China.

Yonomoto, T., H. Nakamura, M. Suzuki, H. Asaka, M. Kondo, I. Ohtsu, Y. Shibamoto, Y. Kukita, R. R. Schultz, G. E. McCreery, J. M. Cozzuol, C. P. Liou, and G. Rhee, Summary Report ROSA-AP600 Program, JAERI-memo 13-009, 2001.

Patents: None to date.

\section{Presentations/Papers Created Under this Project:}

1. Hiral Kadakia, Brian Williams, William Phoenix, and Richard R. Schultz, 2006, "Advanced Reactor Passive Emergency Core Cooling System Stratified Flow Experiments and Characterization of Condensation Induced Water Hammer, Project No: DE-FG07-03ID14500," presented at the American Nuclear Society (ANS) 2006 Winter Meeting, November 12 - 16, Albuquerque, NM.

2. Hiral Kadakia, Brian Williams, William Phoenix, and Richard R. Schultz, 2006, "Design and Calibration of Heated Concentric Low Flow Thermal Velocimeter for the Measurement of Single-Phase Flow," in Proceedings of the $9^{\text {th }}$ AIAA/ASME Joint Thermophysics and Heat Transfer Conference, June 5-8, San Francisco, CA.

3. Hiral Kadakia, Brian Williams, Richard R. Schultz, and Jim C. P. Liou, 2005, “Advanced Reactor Passive Emergency Core Cooling System Stratified Flow Experiments, Project No: DE-FG07-03ID14500," presented at the American Nuclear Society (ANS) 2005 Winter Meeting, November 15, Washington, D.C.

4. Liou, Jim C. P., Donald L. Parks, Richard R. Schultz, and Brian G. Williams, 2005, "Stratified Flows in Horizontal Piping Systems of Passive Emergency Core Cooling Systems," presented at the International Conference on Nuclear Engineering (ICONE13), May 16-20, Beijing, China. 
5. B. Williams, J. C. P. Liou, H. Kadakia, and R. Schultz, 2005, “Advanced Reactor Passive Emergency Core Cooling System Stratified Flow Experiments," presented at the IAEA's Second Research Coordination Meeting on the CRP on Natural Circulation Phenomena, Modeling, and Reliability of Passive Safety Systems that Utilize Natural Circulation, August 29 - September 2, Oregon State University, Corvallis, OR.

6. Hiral Kadakia, Brian Williams, Richard R. Schultz, and Jim C. P. Liou, 2005, "Advanced Reactor Passive Emergency Core Cooling System Stratified Flow Experiments, Project No: DE-FG07-03ID14500," presented at the American Nuclear Society (ANS) 2005 Winter Meeting, November 15, Washington, D.C.

7. Liou, C. P., Stephens, A. L., and Schultz, R. R., 2004, "Stratified Flow Experiments Pertaining to Advanced LWR Rec=actor Passive Safety System Design," ASME/JSME 2004 Pressure Vessel \& Piping Conference, American Society of Mechanical Engineers, San Diego, California, July

8. Stephens, A. L., Liou, C. P., Schultz, R. R., and Kadakia, H. J., 2004, "Characterizing Stratified Flow in Passive Emergency Core Cooling Systems of Light Water Reactors," ANS 2004 Winter Meeting and Nuclear Technology Exposition, American Nuclear Society, Washington, D. C. 


\section{APPENDIX}

\section{Landscape Figure of TPFL Schematic}




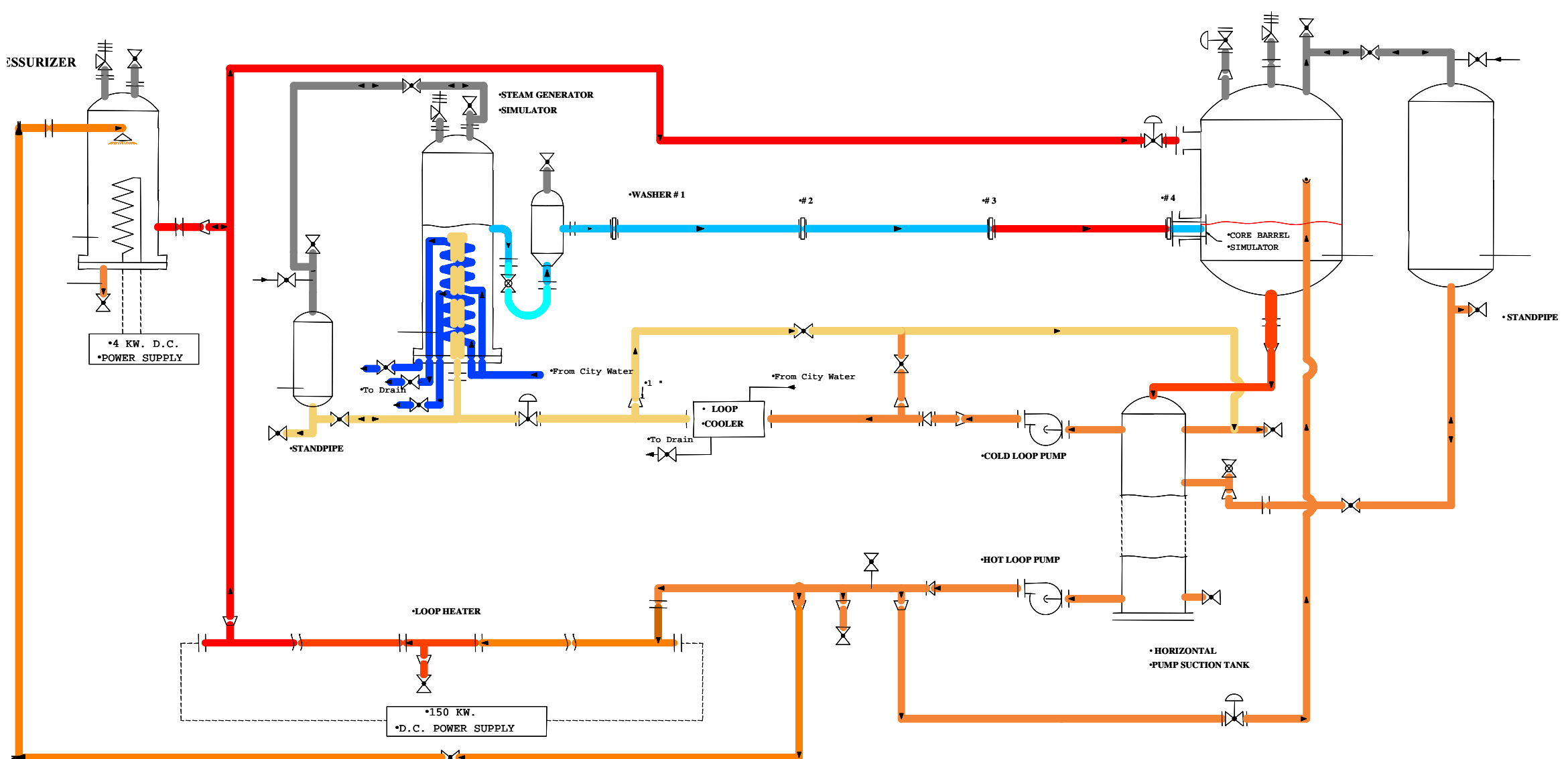

